\title{
Is uterine prolapse a cause of primary infertility?
}

\author{
Uterin prolapsus infertilite nedeni olabilir mi?
}

Rajiv Mahendru

Department of Obstetrics and Gynecology, Mmimsr, Mullana, Ambala, Haryana, India

\section{Abstract}

Presented in this report is apparently the first case of its kind in the medical literature where a woman with 11 years of primary infertility not only conceived following conservative surgery for uterine prolapse but also had a successful obstetrical outcome.

(J Turkish-German Gynecol Assoc 2010; 11: 158-9)

Key words: Uterine prolapse, primary infertility, cervicopexy

Received: 15 December, $2009 \quad$ Accepted: 24January, 2010

\section{Özet}

Bu vaka tbbi literaturde bildirilen ve 11 yıllık primer infertilitesi olup tedavi ile hem bu sorunu hem de obstetrik problemleri düzelmiş olan ilk vakadır. (J Turkish-German Gynecol Assoc 2010; 11: 158-9)

Anahtar kelimeler: Uterin prolapsus, primer infertilite, servikopeksi

Geliş Tarihi: 15 Aralık 2009

Kabul Tarihi: 24 Ocak 2010

\section{Introduction}

Uterovaginal prolapse is mostly attributed to childbirth injury, but paradoxically, hardly any data is available as to prolapse being a cause of infertility. Preservation of fertility is one of the criteria deciding the choice of management, and the surgical procedure offered depends upon the age of the patient and her desire for preservation of menstrual and reproductive capabilities. However, in our case the question was not just of preservation but rather the initiation of fertility.

\section{Case Report}

Written consent was obtained from the patient and the Departmental Ethical Committee approved this report.

A case is presented of a patient aged 32 years, who reported with complaints of primary infertility for 11 years and a mass protruding at the vaginal introitus since 8 years.

The wife of a non-smoker, non-alcholic office clerk, she had lived with her husband since 11 years and there was no history of any coital difficulties or any menstrual abnormalities. She had no chronic cough and no urinary or bowel problems. Her past history revealed a history of management of infertility; the husband's semen analysis was normal, she had had a dilatation and curettage about 9 years previously and the histo-pathology reported the secretory phase of the endometrium. Her fallopian tubes were patent on hysterosalpingography. Other infertility investigations were also normal. Four years previously, she had had Intra-Uterine Insemination in two cycles with the husband's semen but that exercise also proved futile. On examination, she was of average build and height with normal pulse and blood pressure. Her respiratory, cardio-vascular systems and per-abdomen examination did not reveal any abnormality.

Pelvic examination findings were: cervix Iprotruding out of the vaginal introitus with normal sized uterus in the vaginal axis (cervical length- $2.5 \mathrm{~cm}$ and total utero-cervical length-7 cm).

Her routine investigations and the couple's infertility profile were normal and the only positive clinical finding was third degree uterine prolapse. Based on the above review, repair of the prolapse was planned by adopting a conservative approach. The trans abdominal route was followed and bilateral slings of rectus sheath strips were carved out with free medial ends and lateral ends kept intact and then tied on the anterior surface of the exposed cervix, traversing retro-peritoneally almost parallel to the round ligaments (Purandre's Cervicopexy under spinal anaesthesia). The patient was discharged on the fourth day and the subcuticular sutures were removed on her revisit on the seventh day. The post-operative period was uneventful. Regular follow-up confirmed symptomatic \& clinical relief from the prolapse.

About five months later, the patient missed her periods and tested positive for hCG. Her routine ante-natal visits were uneventful. At term, Lower Segment Caesarean Section was performed with no difficulty encountered during surgery and she was delivered of a male child. of 2500 grams. Regular follow-up after caesarean, to date ( 9 months), she has no complaints at allrelating to genital prolapse. 


\section{Discussion}

Genital prolapse is a disorder of pelvic support and is one of the most frequent problems encountered in day to day gynaecological practice, as our social and cultural background predisposes this condition to occur at an age earlier than in any other part of the world (1). Many approaches have been performed for normal anatomic restoration of the prolapsed organ to preserve the uterine function, allowing future child bearing. The age old Manchester-Fothergill procedure may lead to cervical incompetence culminating in miscarriages \& premature deliveries (2). Moreover, the importance of conserving the cervix for conception has also been realised1, though of an optimal length (3). The first report of a few successful pregnancies ( 5 out of 19) was reported was of a sling surgery :sacro-spinous fixation (4). Tio date, review of the literature does not show even a single case where uterine prolapse could be ascertained as a cause for infertility.

\section{Conclusion}

In those cases of unexplained infertility with concurrent uterine prolapse, conservative surgery of the latter, by means of sling supports not only relieves the symptoms of the descensus, but may also help in achieving conception with a successful outcome, thereby curing the primary problem of long standing nulliparity. This option needs further evaluation, so that it can be offered to suitable candidates.

\section{Conflict of interest}

No conflict of interest is declared by authors.

\section{R eferences}

1. Allahbadia GN. Reproductive Performance Following Sleeve Excision Anastomosis Operation for Genital Prolapse. Australia and New Zealand J ournal of Obstetrics and Gynaecology.2008; 32: 149-53.

2. Randhawa AJ. Uterovaginal prolapse in adolescents.International J ournal of Gynaecology \& Obstetrics.2007; 99; 244.

3. Ikedife $D$. Treatment of primary infertility attributed to a long vaginal cervix. J ournal of Obstetrics and Gynaecology.1991; 11: 61-2.

4. Kovac SR, Crivkshank SH. Successful Pregnancies and vaginal deliveries after Sacrospinous Uterosacral fixation in five of nineteen patients. Am J Obstet Gynecol.1993; 168(6 pt 1):1778-83. 